\title{
Wound Botulism
}

National Cancer Institute

\section{Source}

National Cancer Institute. Wound Botulism. NCI Thesaurus. Code C128342.

Botulism that is caused by toxin that is produced in a wound contaminated with Clostridium botulinum. 